and re-organization at Rheola, followed by a period during which Rheola's production would be stepped up and Milton's run down to the point of complete closurethe run-down being phased and controlled so as to synchronize with a gradual expansion of Rheola. A careful timetable was worked out for the announcement of the closure, and a National Industrial Officer of the union principally affected was invited to a meeting at the head office. The operation was helped by the reputation of the general manager of personnel, but much depended on a small group of senior executives being able to work closely together as a team and maintain complete secrecy towards their colleagues while doing so. Whon eventualiy revealed, the arrangement evoked surprisingly little emotional reaction from colleagues who were excluded. An important feature of the planning was that the personnel function was brought in at an earlier stage. A notable feature was the manner in which general management at head office and operating management at plant-level accepted the need for careful and considered policies in the field of personnel and public relations, and co-operated readily when necessary in applying them. The period of negotiations was the most searching for the personnel division, and the foundations of the plan were tested to the full. They withstood that test because the unions were already confident of finding accessibility and flexibility, realism, sincerity and good faith. The strain was held with equal resilience at the plant-level, where relations of mutual respect had long prevailed. This background was also of crucial importance during the period of redundancy and run-down, key factors in the creation of this tough and resilient framework of plant relations being the character and authority of the convener and the good sense and insight of the managers with whom he had to deal. This sort of industrial situation, which makes it possible to cope successfully with great change or great trouble, cannot be built up overnight.

\section{Films on Chemistry and Related Sciences}

A COMPREHENSIVE list of films and filmstrips on chemistry and related topics is once again available under the title Index of Chemistry Films : a Comprehensive List of Films and Filmstrips on Chemistry and Related Topics (Fourth edition. Pp. xii +268 . London: the Royal Institute of Chemistry, 1965. 7s.6d.). This new edition contains up-to-date details of about 1,400 films and 400 filmstrips on chemistry and related subjects, fully classified in each category, together with the addresses of the various distributors concerned, list of titles, date of production, details of nature of film : black-and-white or colour, with sound-track or silent, running time, gauge, free loan or hire, etc.; in the case of filmstrips much the same information is given, but it is pointed out that many are available only for sale, although a majority of distributors offer a preview service to prospective purchasers. In the case of films, not the least valuable part of this catalogue is the brief synopsis of the subject-matter under each title; filmstrips are regarded as a formal teaching aid and no description of contents is given since the titlos themselves are usually sufficient to convey such information; in this Index the scope of filmstrips listed is confined to the more strictly chemical material. In an appendix there is a useful alphabetical list of titles for quick reference which includes both films and filmstrips mentioned in the text. In a similar context another catalogue of films has recently been published (Films on Science and Mathematics available on loan from the O.E.C.D. Film Library (Science Section). Pp. 54. Paris: Organization for Economic Co-operation and Development, 1965). This includes 463 titles, classified under headings: PhysicsChemistry; Mathematics; Biology; General Science. A separate section lists 117 titles of cartridge-loaded 8-mm silent films, suitable for showing on the Technicolor 800 projector only. Most of the other films are $16 \mathrm{~mm}$.
Summary details of the nature of each film are included, but no synopsis of contents.

\section{Rehabilitation of Schizophrenic Patients}

Ar the present time about three-quarters of the patients in mental hospitals in England and Wales have been resident for two years or more. Most of them are suffering from a form of schizophrenia. Many of them are comparatively young and some have only a relatively mild, residual form of illness, but this is incapacitating enough to make ordinary life difficult both for the patients and for those associating with them. The problem of rehabilitation is formidable. In The Industrial Rehabilitation of Long-stay Schizophrenic Patients (Medical Research Council Memorandum No. 42. London: H.M.S.O., 1964. 4s. 6d.). Drs. J. K. Wing, D. H. Bennett and J. Denham describe a project in which they explored the extent to which a representative group of moderately disabled schizophrenic men under the age of 60 could be resettleel outside hospital in satisfactory employment, with the help of a course at an Industrial Rehabilitation Unit, and intensive after-care. These men were carefully observed both during their course and afterwards, and their behaviour and achievements compared with those of a non-schizophrenic control group. The results are on the whole encouraging: of the 45 patients studied just less than half were working satisfactorily one year after discharge from the Industrial Rehabilitation Unit, 10 of them in sheltered employment. A few others were working but their adjustment was precarious. The study pinpoints a number of matters of practical importance in rehabilitation. Foremost is the fact that after-care of a particularly thorough kind is required if both the individual concerned and his relatives are to be sustained through periods of difficulty. More opportunities for sheltered employment are also required, and perhaps more places in Industrial Rehabilitation Units, though here, in particular, it is obviously important that there should not be too high a proportion of mentally ill patients since the beneficial effects of the new environment might thus be lessened. There is finally the problem of lodgings: in this study the men concerned had greater difficulty in living than in working outside hospital. If, however, adequate arrangements are made to cater for these various needs, there seems to be every reason to expect that a small selected group of long-stay schizophrenic patients can be successfully resettled in work.

\section{Clinical Pharmacology Awards}

THREE medical schools in the United States will each receive a $\$ 100,000$ dollars award to support a Section of Clinical Pharmacology under grants now announced by the Burroughs Wellcome Fund of Tuckahoe, New York. These awards, which run for five years, are given to support a "Burroughs Wellcome Scholar in Clinical Pharmacology" in each medical school. This year's recipients are Southwestern Medical School of the University of Texas on behalf of Dr. J. Richard Crout, the College of Medicine of the State University of Iowa on behalf of Dr. William R. Wilson and the School of Medicine of Vanderbilt Univer. sity on behalf of Dr. John A. Oates. These three awards bring the number of Burroughs Wellcome Scholars in Clinical Pharmacology to nine since the programme was started in 1959. The purpose of the Clinical Pharmacology Awards is "to assist medical schools in providing laboratories and clinics where students may learn under a first-class scientist and teacher to apply basic scientific knowledge and techniquos to the study of clinical pharmacology, and to develop thereby clinical investigators who are capable of evaluating critically the therapeutic efficacy and mechanisms of actions of drugs".

\section{Postgraduate Course in Ecology}

A NEw, one-year postgraduate course in ecology, leading to the M.Sc. degree, is being offered by the University of 